\title{
Psychological Factors to Retain Teachers in Education in Namibia
}

\section{Wesley Reginald Pieters}

\section{Abstract}

Teachers are resigning at an alarming rate. It is feared that this will disrupt the education system, economic growth and development of Namibia. Considering the critical importance of education in any country, teacher attrition needs to be investigated and vital recommendations presented to prevent an economic collapse. The purpose of this study was to investigate the relationship between psychological conditions, sense of calling, organisational commitment and turnover intention of teachers in Namibia. Due to the lack of qualified teachers, work stress increases and high learner failure rates continue. When teachers experience a sense of calling, meaning in their work, become more committed, they would want to stay, work hard, reducing work stress and reducing learner failure rates. This study made use of a questionnaire to collect data on the biographical details, psychological conditions, sense of calling, organisational commitment and turnover intention of teachers at schools in Namibia. The sample consisted of teachers from the Omaheke, Oshana and Oshikoto regions $(n=288)$. These variables recorded significant relationships with turnover intention. Affective commitment, sense of calling (prosocial orientation search; transcendent summons search; purposeful work presence; purposeful work search), and psychological meaningfulness significantly predicted turnover intention. These positive psychological states can improve teachers productivity, work engagement and learners performance. Schools and teachers need to engage in job crafting and job enrichment, enhancing affective commitment, enhancing the meaning and purpose of teaching in Namibia, and ensuring that teachers remain in the teaching profession.

Keywords: Psychological conditions, sense of calling, organisational commitment, turnover intention 


\section{Introduction}

Xaba (2003) indicated that teacher turnover results in shortages in educator supply, cost regarding recruitment and training, poor learner performance as well as classroom overcrowding. Even though there are many teachers graduating annually, schools in Namibia continue to experience teacher shortages. Turnover of teachers results from poor working conditions and poor work related benefits. The lack of qualified teachers in Namibian school results in increased work stress for teachers that remain in the schools and high learner failure rates (Nambundunga 2016). This study aims to investigate some of the factors that influence teacher turnover intention within Namibia.

In a report for the New Era Newspaper, Haufiku (2014) indicated that the Ministry of Education confirmed that in some schools, the teacher-learner ratio is 1:50. It was also noted that, due to the perceived low salaries paid to teachers, many teachers have ventured into the private sector in search of better remuneration. These financially challenging circumstances can lead to organisational frustration and turnover intention. Teachers resigning from public schools to move to private schools add to the frustration being experienced. The outflow of teachers from public schools is evident by the number of vacancies advertised on a regular basis.

A total number of 2569 vacant teaching posts were advertised towards the end of $2017^{1}$.

This massive number of vacant posts indicates the dire need for more teachers in Namibia. This critical situation is further amplified by the fact that there are vacancies for qualified, underqualified and unqualified teachers. There are different factors that influence teachers' decision to leave.

Some factors that impact on turnover intention include: lack of satisfaction in terms of autonomy (not being included in decision making or allowed to direct work related activities), lack of good relations between supervisors and employees and low levels of perceived competence (not believing that you have the necessary abilities to execute your work duties) (Kim \& Stoner 2008; Rothmann, Diedericks \& Swart 2013). Factors that also impact on turnover intention include: job satisfaction, specifically related to the working environment, satisfaction with pay, relations with colleagues, advancement opportunities and satisfaction with opportunities to utilise your skills and finding meaning in your work (Choudhury \& Gupta 2011; Nouri \&

${ }^{1}$ See, http://www.informante.web.na/uploads/pdfs/TeachingPosts.pdf. 


\section{Wesley Reginald Pieters}

Parker 2013). This study will focus on psychological conditions (psychological meaningfulness, psychological safety, psychological availability), sense of calling (search and presence), organisational commitment (normative, continuance and affective commitment), and how these factors impact turnover intention of teachers within selected regions in Namibia.

The article will start by defining these different variables to help the reader better understand these concepts. The literature section will discuss each variable as well as how these variables are interrelated and conclude with the hypotheses that this study aims to test. The methodology and results section will be discussed after that. The literature and results will be used to further discuss the relationship/s between the variables, draw conclusions, and make recommendations on how to retain teachers within the education sector.

\section{Literature Review}

\subsection{Psychological Conditions}

Psychological conditions are composed of psychological meaningfulness, psychological safety, and psychological availability. These could be briefly described as follows.

Psychological meaningfulness has to do with whether the employee regards his/ her work as important to themselves and significant in terms of the organisation and the people that they affect with their work. Kahn (1990) defined psychological meaningfulness as a return on investment through physical, cognitive or emotional work done. This indicates that there is a certain degree of fairness, significant reward for significant effort which includes all aspects of work.

Psychological safety assesses whether employees feel safe to make mistakes, express themselves and try out new things without the fear of being ridiculed or embarrassed for doing it wrongly whilst learning. Psychological safety can also be regarded as a safe environment for learning, exposure and growth (Khan 1990).

Psychological availability deals with being confident in your abilities to: handle different demands, think clearly about work activities, handle emotions well at work, and believe that you can execute your work effectively (Khan 
1990). The dimensions of psychological condition will be discussed in more detail below and focus specifically on how these dimensions influence other job experiences.

\subsubsection{Psychological Meaningfulness}

Job enrichment and work - role fit were found to be related to psychological meaningfulness (May, Gilson \& Harter 2004; Rothmann \& Welsh 2013). This indicates that when employees experience autonomy, skill variety, task significance, feedback and task identity, as well as having significant fit between their skills, ability and the requirements of the work, they would experience higher levels of meaning in their work. Allan, Duffy and Collisson (2016) found a positive relationship between meaningful work and task significance. If employees are required to do work that is important, they would also experience a higher level of meaning. Similar positive relations were also found by other studies.

Rothmann and Welsh (2013) found that rewards, supervisor relations, and organisational support were positively related to psychological meaningfulness. This means that when employees get sufficient rewards for their work effort, have good relations with supervisors, and receive the necessary support from the organisation (wages, medical benefits, mutual respect), the meaning that they experience increases. Apart from these methods to enhance psychological meaningfulness in work, employees may also engage in job crafting.

Job crafting can be achieved by changing the amount of time, energy or attention you allocate to a certain task, for example, assisting a colleague to do lesson planning and he/she assisting you with your filing duties. Job crafting can be achieved by changing your relationships at work, impacting on how, when and with whom you interact whilst doing your job. That is, refraining from interacting with people that tend to have a negative outlook on life and interacting with a colleague that motivates and inspires you to want to do better. Job crafting can be practiced by changing the way employees perceive their jobs, for example, being responsible for sport education. Some teachers may see it as a waste of time whilst others may regards it as teaching young people to take-up an active life style, teaching discipline, dedication, and determination through sport (Berg, Dutton \& Wrzesniewski 2013). It was indicated that job crafting enhances psychological meaningfulness experienced at work 
(Wrzesniewski, LoBuglio, Dutton \& Berg 2013). This means that employees alter their tasks, relations at work and how they see their work. The next section will focus on psychological safety as part of the psychological conditions.

\subsubsection{Psychological Safety}

Psychological safety has to do with the experience of being able to utilise skills and knowledge in a way that you do not need to worry about negative consequences or being ridiculed (Kahn 1990). This has to do with working in a safe environment, not being afraid to make a mistake or concerned about colleagues making fun of you because of the mistake and possibly an environment where growth and learning can take place through experience. Psychological safety is also related to other variables.

When employees perceive procedures to be executed equitably and fairly (procedural justice), they would also experience a higher level of psychological safety (Chen, May, Schwoerer \& Augeli 2016). Knowing that procedures will be followed fairly, employees would also be more open to engage in work activities, and ask for guidance since it is regarded as a safe working environment. Apart from having fair and equitable procedures at work, psychological safety can also be enhanced with positive relations.

Psychological safety is enhanced when employees experience good relations with colleagues and supervisors (May et al. 2004). When good relations exist between colleagues and supervisors, employees feel comfortable and honest about their work-related challenges since they experience the working environment as safe and non-judgemental. The third dimension of psychological conditions is psychological availability which will be discussed in the next section.

\subsubsection{Psychological Availability}

Employees that experience psychological availability regard themselves as having the necessary physical, emotional or cognitive resources to engage in work (Kahn 1990). It can also be regarded as competence - believing in your ability to execute your work duties. Having the required resources available enhance employees' perceived level of competence.

It was found that resources are positively related to psychological availability (May et al. 2004). This indicates that if employees have the 
necessary physical, emotional and cognitive resources, they would be better equipped to complete their work activities.

Psychological meaningfulness and psychological availability mediated the relationship between work - role fit, job enrichment, resources, coworker relations and employee engagement (Rothmann \& Welsh 2013). This indicates that employees that experience psychological meaningfulness in their work and believe that they have the necessary resources (physical, emotional and psychical) are more likely to work hard towards the achievement of organisational goals. Sense of calling, another variable being investigated as part of this study, will be discussed in the next section.

\subsection{Sense of Calling}

Employees view their work as a career, job or calling (Bellah, Madsen, Sullivan, Swidler \& Tipton 1985). Employees that regard their work as a calling tend to experience meaning, and this brings about positive work-related behaviour. Wrzesniewski and Dutton (2001) explained that employees that regard their work as a calling tend to be more motivated towards these activities since they carry moral, social and personal importance. This indicates that teachers that regard teaching as a calling tend to teach because of the moral, social and personal importance experienced in education/ teaching.

On the other hand, it was indicated that people experience a sense of calling because they also believe that the work that they do is making the world a better place (Hirschi 2011). Rothmann and Hamukang'andu (2013) found that when employees experience a calling orientation they would also be more engaged in their work. This indicates that when teachers experience a sense of calling they are less likely to want to leave; instead they would want to work towards the goals and objectives of the organisation.

Elaborating further on this, it was found that sense of calling moderated the relationship between organisational frustration and work engagement (Ugwu \& Onyishi 2017). This means that when employees experience a sense of calling, it impacts on their experience of organisational frustration and their level of work engagement. Experiencing a sense of calling allows teachers to work through organisational frustration, understanding their purpose as a teacher and uncompromisingly doing their work. Some employees work to get paid while other may work because of the role they fulfil.

If employees believe that the work that they do is part of their purpose 


\section{Wesley Reginald Pieters}

in life and they have the required skills and abilities to do the job, they experience work - role fit. Work - role fit mediated the relationship between calling orientation and psychological meaningfulness (Rothmann \& Hamukang'andu 2013). This indicates that teachers will experience psychological meaningfulness when they experience a calling orientation which may be enhanced by work - role fit.

Experiencing a sense of calling may indicate that those employees are doing their jobs not only for the tangible benefits. Employees that experience a sense of calling are also more likely to experience job satisfaction (Chen et al. 2016). Doing work that you find meaningful would lead to higher levels of job satisfaction. Cronbach's alpha was recorded for search for calling (.84) and presence of calling (.89) (Willemse \& Deacon 2015). The next section will be discussing organisational commitment, like sense of calling; it enhances employees' decision to stay at the organisation.

\subsection{Organisational Commitment}

Organisational commitment can be defined as the identification that an employee has with the organisation. Organisational commitment is made up of affective, normative and continuance commitment (Allen \& Meyer 1996). Affective commitment, also regarded as the most important aspect of commitment, is defined as a psychological attachment an employee has to the organisation, and wants to remain with the organisation to achieve its goals and objectives. Normative commitment can be defined as a form of commitment due to perceived expectations of loyalty. These are employees that want to remain at the organisation because they perceive a certain level of obligation towards the organisation or colleague(s) for favours being done. Continuance commitment refers to the type of commitment where employees prefer to stay with an organisation due to the perceived loss they would endure if they were to leave. This could be because the organisation is offering certain benefits that would not be available at another organisation (Allen \& Meyer 1996).

Organisational commitment is likely to encourage employees to want to work. Work engagement predicted organisational commitment of call centre employees in South Africa (Simons \& Buitendach 2013). Employees that are engaged in their work will also experience a higher level of organisational commitment. Employees that find pleasure in the work they do are likely to want to remain at the organisation. 
It was found that when employees experience job satisfaction they would also be more committed towards the organisation (affective commitment) (Qureshi, Frank, Lambert, Klahm \& Smith 2017). Ensuring that employees are satisfied with both intrinsic (autonomy, skills utilisations) and extrinsic factors (pay, benefits, and working conditions) would increase their psychological identification with the organisation - wanting to work towards the goals of the organisation. Factors that also enhance organisational commitment are the procedures within the organisation.

A study by Qureshi et al. (2017) found that procedural justice (promotions and performance evaluation) and distributive justice recorded positive relations with affective commitment. When employees regard policies and procedure application within the organisation to be fair with regards to promotion and performance evaluation, they are more likely to become more committed towards the organisation. Employees would also become more committed if rewards and punishment are distributed fairly and consistently (LopezCabarcos, Pinho \& Vazquez-Rodriguez 2015). When employees experience job satisfaction, it's likely to influence other experiences of the work.

When employees experience satisfaction with regards to the nature of the work, supervision, co-workers, promotions and pay, they experience a higher level of normative and affective commitment (Jena 2014). When the job that employees do is meaningful, challenging and satisfying, when they are satisfied with the relations with colleagues and supervisors, opportunities for promotion and pay received, they would want to remain at the organisation. Chang (2015) and O'Donnell, Jayawardana and Jayakody (2012) found that job satisfaction is positively related to organisational commitment. Akomolafe and Olatomide (2013) found that job satisfaction is a significant predictor of organisational commitment of secondary school teachers in Nigeria. When employees experience healthy interactions with colleagues, they are likely to want to remain at the organisation.

Perceived organisational support was found to be positively related to organisational commitment (O'Donnell et al. 2012; Shukla \& Rai 2015). Perceived organisational support was found to improve the relationship between job satisfaction and organisational commitment. Employees that are satisfied and committed are likely to want to do more work that is not necessarily part of their job description.

Employees that experience organisational commitment are more likely to engage in organisational citizenship behaviour (Paul, Bamel \& Garg 2016; 
Huang, You \& Tsai 2012). This indicates that when employees identify with the organisation, they would also want to go above and beyond their call of duty; executing tasks that are not necessarily part of their employment contract or for what they get paid for. The next section will be discussing turnover intention.

\subsection{Turnover Intention}

Turnover intention is when a competent and capable employee decides to leave his/ her current organisation to work for another organisation (Mensele \& Coetzee 2014). Price (2001) indicated that it is a permanent change in membership from one organisation to another. This indicates that this member will no longer be contributing to the success of the specific organisation, but rather work towards the goals and objectives of another organisation. Medina (2012) found that turnover intention is the best predictor of actual turnover. This indicates that when employees have the intention to leave, it is highly likely that they will leave that organisation within a certain amount of time. This intention can be influenced by different factors.

Perceived organisational support and job satisfaction was found to be negatively related to turnover intention (O'Donnell et al. 2012). This indicates that employees that acknowledge that the organisation is providing them with the necessary support would also experience pleasure in their jobs, and in turn want to remain at the organisation. Campbell and Im (2016), Regts and Molleman (2013) also found job satisfaction to be negatively related to turnover intention. When employees are treated fairly they are likely to want to remain at the organisation.

It was found that fair treatment is negatively related to turnover intention (Campbell \& Im 2016). When employees regard interactions, policies and procedure application to be fair, it would also be less likely that they would want to leave. These employees are likely to be performing their jobs effectively.

Job performance was found to be negatively related to turnover intention (Dane \& Brummel 2013). This indicates that when employees want to leave, they are also less likely to perform at acceptable levels and performance would also be low. When employees experience turnover intention, it will negatively affect organisational performance, and this emphasises the importance of dealing with turnover intention of employees urgently. 
Employees that experience turnover intention are likely to also experience lower levels of intrinsic and extrinsic motivation, emotional exhaustion and depersonalisation (Kim 2015). This indicates that when organisations go through change, it negatively impacts on the employees' motivation and job demands resulting in exhaustion, depersonalisation (burnout) and turnover intention. Supervisory support may act as a buffer against these negative job experiences.

It was found that employees that experience supervisory support and autonomy in their work tend to experience lower levels of turnover intention (Cho \& Song 2017). This indicates that employees that experience support from supervisors would want to remain at the organisation, because of open communication, it allows employees to be part of the decision making processes, provides encouragement, the sharing of critical information, and because it allows employees a certain degree of control regarding his or her work tasks, including a certain level of independence and discretion.

Some jobs may be more taxing than others. Emotional labour, being required to display organisationally acceptable facial and bodily expressions and not necessarily the genuine feelings or emotions, is positively related to turnover intention (Cho \& Song 2017). People working in the service industry, just like teachers, experience emotional dissonance - the mismatch between the expected and genuine feelings and emotions. Cognitive dissonance may result in turnover intention making it important for employees in the service industry to have a platform to communicate their frustrations and to raise their concerns. In the next section a discussion will follow about how the variables in this study are related and interrelated.

\subsection{Psychological Conditions, Sense of Calling, Organisa- tional Commitment and Turnover Intention}

Based on the link between psychological meaningfulness and some other organisational outcomes like productivity, low absenteeism, and job satisfaction, it is likely for psychological meaningfulness to also have a negative relationship with turnover intention (Berg et al. 2013; Wrzesniewski et al. 2013). When these employees experience positive work outcomes, they are likely to want to remain at the organisation.

Calling orientation was positively related to co-worker relations, meaningful work, work engagement and performance. Calling orientation (- 
.66) and meaningful work (-.50) were negatively related to turnover intention (Fouche, Rothmann \& Van der Vyver 2017). It was found that teachers who experience a sense of calling are also likely to experience meaningfulness in their work (Ugwu \& Onyishi 2017). When teachers experience meaningfulness in their work, they are also likely to become more engaged in their work. The same positive relationship was found between work engagement and sense of calling. Marques (2013) found a negative relationship between work engagement and turnover intention of university staff.

Another study by Willemse and Deacon (2015) found that search for calling and presence of calling recorded a positive relationship with meaningful work (Fouche et al. 2017). Employees experiencing a sense of calling tend to work not solely for the tangible benefits, but also the psychological meaning and personal growth attached to completing their work. In another study, a positive relationship was found between sense of calling, job satisfaction and turnover intention (Chen et al. 2016). This indicates that employees who regard their jobs as a calling would enjoy what they do, and would be less likely to want to leave. Employees that experience satisfaction in their work are more likely to experience organisational commitment and work engagement, wanting to remain at the organisation and work towards the success of the organisation (Brunetto, Teo, Shacklock \& Farr-Wharton 2012). On the other hand, a negative relationship was found between organisational commitment and intention to leave (O'Donnell et al. 2012; Park, Christie \& Sype 2014). This means that employees that identify with the organisation would want to remain, and work towards the success of the organisation.

Based on the literature discussed above, the following hypotheses have been developed.

Hypothesis 1: Psychological conditions have a negative relationship with turnover intention.

Hypothesis 2: Sense of calling has a negative relationship with turnover intention.

Hypothesis 3: Organisational commitment has a negative relationship with turnover intention.

Hypothesis 4: Psychological conditions, sense of calling and organisational commitment are significant predictors of turnover intention. 


\section{Methodology}

Making use of a cross-sectional research design, data was collected on psychological conditions, sense of calling, organisational commitment and turnover intention of teachers (Creswell 2003). A questionnaire was used to collect the data.

Permission was obtained from the Permanent Secretary of the Ministry of Education. Permission was also requested and obtained from regional education directors in the Ministry of Education, Arts and Culture - before liaising with principals at the different schools to assist with the collection, distribution and return of the questionnaires. Teachers were in no way forced into participating, and were informed about their right to withdraw from the study at any time.

The data was analysed using SPSS Version 24.0 (SPSS, 2016). Making use of descriptive statistics, the mean and standard deviation was calculated. Cronbach's alpha coefficients $(\alpha)$ were used to determine the internal validity of the measuring instruments. Pearson's product - moment correlation was used to determine the relationship between the different variables. Making use of Stepwise Multiple Regression, this study investigated if psychological conditions, sense of calling, and organisational commitment, predicted turnover intention of teachers in the regions under study. It was also decided to set the value of significance at $95 \%$ confidence interval level $(p<$ $0,05)$. Effect sizes were used to determine practical significance of the findings (Steyn 1999) with a cut-off point of 0,30 (medium effect) that was set for the practical significance of correlation coefficient (Cohen 1988).

\subsection{Participants}

The sample consisted of $n=288$ teachers, heads of departments and principals from primary and secondary schools in the Omaheke, Oshana and Oshikoto regions of Namibia. Based on Table 1, most teachers are females $(n=185$, $64.2 \%), 21.2 \%(n=61)$ are 51 years and older, $37.8 \%(n=109)$ have worked for 16 years and more, $42.4 \%(n=122)$ have obtained a diploma, $34 \%(n=79)$ have 1-2 children, and $48 \%(n=139)$ are single. The remainder of the biographical information is presented in Table 1 below. 
Wesley Reginald Pieters

\section{Table 1:}

Biographical details of sample

\begin{tabular}{|c|c|c|c|}
\hline Category: & Item: & Frequency: & Percentage: \\
\hline \multirow[t]{3}{*}{ GENDER: } & Male: & 102 & 35.4 \\
\hline & Female: & 185 & 64.2 \\
\hline & $\begin{array}{l}\text { Missing } \\
\text { values: }\end{array}$ & 1 & 0.4 \\
\hline \multirow[t]{9}{*}{ AGE: } & Below 24: & 8 & 2.8 \\
\hline & $24-28$ & 58 & 20.1 \\
\hline & $29-31$ & 29 & 10.1 \\
\hline & $32-35$ & 29 & 10.1 \\
\hline & $36-40$ & 37 & 12.8 \\
\hline & $41-45$ & 28 & 9.7 \\
\hline & $46-50$ & 33 & 11.5 \\
\hline & 51 and older & 61 & 21.2 \\
\hline & $\begin{array}{l}\text { Missing } \\
\text { values }\end{array}$ & 5 & 1.7 \\
\hline \multirow[t]{9}{*}{ TENURE: } & $\begin{array}{l}\text { Less than } 1 \\
\text { year }\end{array}$ & 12 & 4.2 \\
\hline & $1-2$ & 26 & 9.0 \\
\hline & $3-4$ & 36 & 12.5 \\
\hline & $5-6$ & 35 & 12.2 \\
\hline & $7-8$ & 23 & 8.0 \\
\hline & $9-11$ & 23 & 8.0 \\
\hline & $12-15$ & 22 & 7.6 \\
\hline & 16 and more & 109 & 37.8 \\
\hline & $\begin{array}{l}\text { Missing } \\
\text { values }\end{array}$ & 2 & 0.7 \\
\hline \multirow[t]{9}{*}{ QUALIFICATIONS: } & Grade 12 & 53 & 18.4 \\
\hline & Certificate & 9 & 3.1 \\
\hline & Diploma & 122 & 2.4 \\
\hline & Degree & 58 & 20.1 \\
\hline & Honours & 38 & 13.2 \\
\hline & Degree & & \\
\hline & Master's & 1 & 0.3 \\
\hline & Degree & & \\
\hline & $\mathrm{PhD}$ & 1 & 0.3 \\
\hline
\end{tabular}


NUMBER OF

\section{DEPENDENTS}

(children):
Missing

values

None

1-2

3-4

5-6

7-9

10 and more

Missing

values

MARITAL STATUS: Single

Married

Divorced

Widowed

Missing

values

RANK:

REGION:

values
Teacher

Head

Department

Principal

Missing

Omaheke

Oshana

Oshikoto

Missing

values
6

54

2.1

18.8

34.0

27.4

11.5

2.8

3.1

2.4

139

137

48.3

47.9

4

1.4

6

2.1

2

0.7

84.4

8.7

5.9

1.0

3

125

43.4

5.6

50.7

0.3

\section{TOTAL:}

\subsection{Measuring Instruments}

A biographical instrument was developed by the researcher to obtain information about the participants' gender, age, rank, tenure, highest qualification obtained, number of dependents (children) and marital status. 
The Psychological Conditions Questionnaire (PCQ) developed by May et al. (2004) measures psychological conditions namely psychological meaningfulness, psychological safety and psychological availability. Psychological meaningfulness measures how meaningful employees regard their jobs ('My job activities are significant to me'). Psychological safety measures how comfortable employees felt to express themselves at work ('I am afraid to express my opinions at work'). Psychological availability assesses the extent to which employees are confident in their abilities when completing their work ('I am confident in my ability to deal with problems that come up at work'). The response format ranges from 1 strongly disagree to 7 strongly agree. May et al. (2004) found this instrument to be reliable (psychological meaningfulness- .90; psychological safety- .71, and psychological availability$.85)$.

The Calling and Vocational Questionnaire was developed by Dik, Eldridge, Steger and Duffy (2012), and comprises 24 items to assess participants' presence and search for calling in each subscale of the construct. This questionnaire measures: Presence of Transcendent Summons ('I believe that I have been called to my current line of work'), Search for Transcendent Summons ('I'm searching for my calling in my career'), Presence of Purposeful Work ('My work helps me live out my life's purpose'), Search for Purposeful Work ('I am looking for work that will help me live out my life's purpose.'), Presence of Prosocial Orientation ('I am trying to find a career that ultimately makes the world a better place'), and Search for Prosocial Orientation ('The most important aspect of my career is its role in helping to meet the needs of others'). The response format ranged from 1- Not at all true of me; 2- Somewhat true of me; 3-Mostly true of me; and 4-Absolutely true of $m e$. This instrument was found to be reliable, and recorded the following Cronbach alpha's: (Presence for Transcendent Summons- .80, Search for Transcendent Summons- .87, Presence of Purposeful Work- .81, Search for Purposeful Work- .67, Presence of Prosocial Orientation- .80, and Search for Prosocial Orientation- .81) (O’Neal 2017).

The Organisational Commitment Questionnaire (OCQ) was developed by Allen and Meyer (1984) to assess employees' level of commitment towards the organisation. The questionnaire consists of 18 items revised in 1997 measuring normative, effective and continuance commitment. The self-report questionnaire has a Likert response scale from 1 to 5 (1 strongly disagree to 5 - strongly agree). The scale measures: continuance 
commitment ('one of the few negative consequences of leaving this organisation would be the scarcity of available alternatives'), normative commitment ('I would feel guilty if I leave my organisation right now') and affective commitment ('I do not feel like 'part of the family' at my organisation') commitment. Overall, Cronbach's alphas of .80 were found by Viljoen and Rothmann (2009).

The Turnover Intention Scale (TIS-6), validated by Bothma and Roodt (2013), was used to measure turnover intention. This instrument measures employees' intention to either stay with the organisation or leave the organisation. It makes use of a seven point response scale ranging from 1 (never/ to no extend) to 7 (most of the time/ to a large extend). Bothma and Roodt (2013) found Cronbach's alpha of .80 (TIS-6), and confirmed the criterion-predictive validity.

\section{Results}

\subsection{Descriptive Statistics, Cronbach Alphas and Correlations}

Psychological meaningfulness recorded a mean of 36.10, psychological availability 29.30, Search for Transcendent Summons 10.27, Presence of Purposeful work 13.26, Search for Purposeful Work 7.40, Presence of Prosocial Orientation 10.43, Search for Prosocial Orientation 10.46, Normative commitment 17.65, Affective commitment 15.26 and Turnover intention 7.52. The following standard deviations were recorded: Psychological meaningfulness 6.75, psychological availability 5.57, Search for Transcendent Summons 3.31, Presence of Purposeful work 2.41, Search for Purposeful Work 2.87, Presence of Prosocial Orientation 1.59, Search for Prosocial Orientation 3.42, Normative commitment 4.03, Affective commitment 3.27 and Turnover intention 3.54.

Psychological conditions (psychological meaningfulness, $\alpha=.93$; psycholo-gical availability $\alpha=.91$ ) was found to be reliable for this study. Psychological safety was found to be unreliable in this study and thus excluded from further analysis.

The Calling and Vocational Questionnaire was also found to be reliable for transcendent summons search (.75), purposeful work presence (.75), purposeful work search (.77), prosocial orientation presence (.70), and 


\section{Wesley Reginald Pieters}

prosocial orientation search (.74). Transcendent summons presence was found to be unreliable for this study, and was excluded from the study.

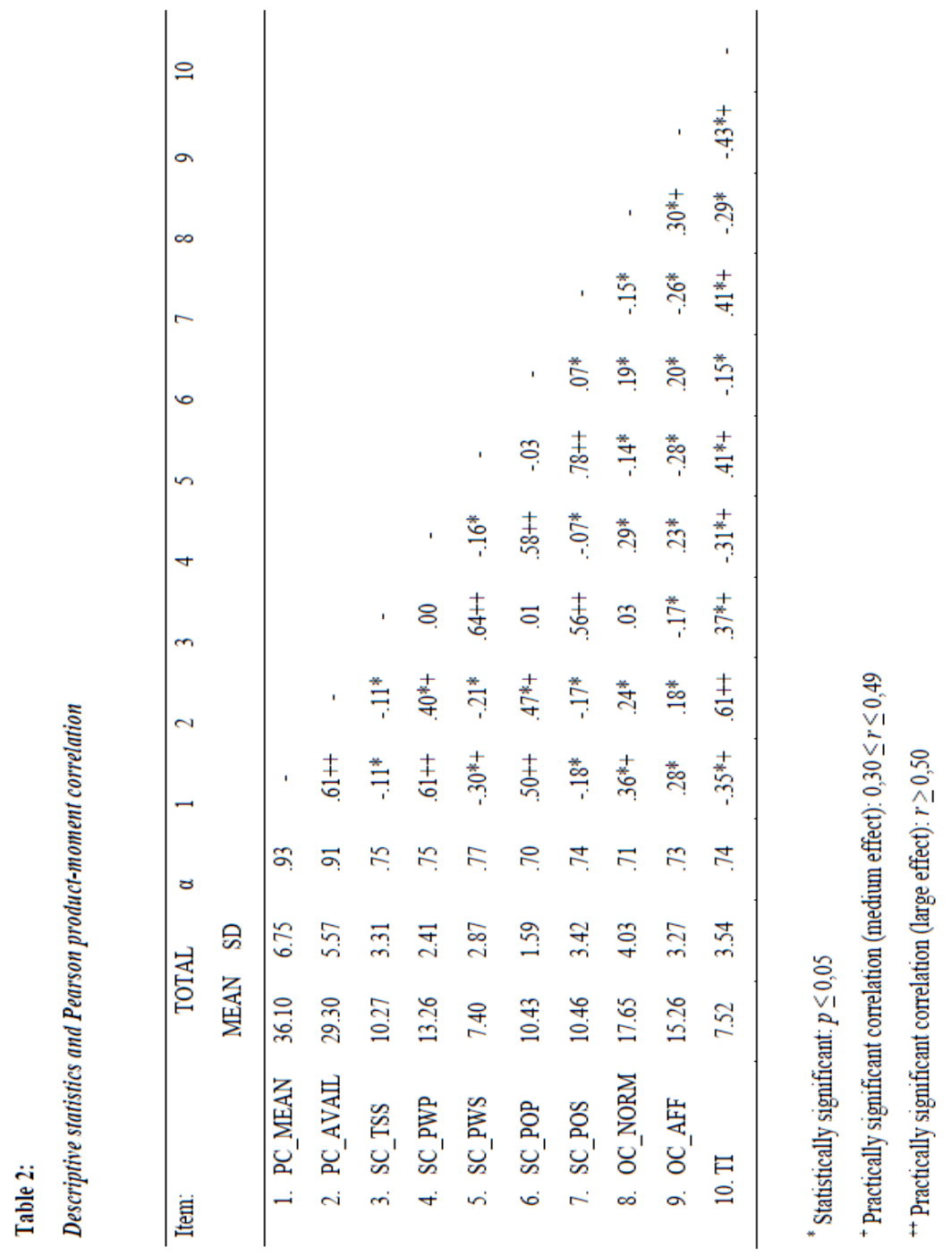


1. PC_MEAN= Psychological conditions (Psychological Meaning)

2. PC_AVA= Psychological conditions (Psychological Availability)

3. SC_TSS $=$ Sense of Calling (Search for Transcendent Summons)

4. SC_PWP $=$ Sense of Calling (Purposeful Work Presence)

5. $\quad$ SC_PWS $=$ Sense of Calling (Purposeful Work Search)

6. $\quad$ SC_POP $=$ Sense of Calling (Presence Of Prosocial Orientation)

7. SC_POS $=$ Sense of Calling (Search Of Prosocial orientation)

8. OC_NORM= Organisational commitment (Normative commitment)

9. OC_AFF= Organisational commitment (Affective commitment)

10. $\mathrm{TI}=$ Turnover Intention

Organisational commitment was also found to be reliable for normative commitment (.71) and affective commitment (.73). Continuance commitment did not meet the requirements of .70 for reliability, and will also not be used in the final analyses of this study.

The TIS- 6 was found to be reliable in a South African context. The Turnover intention scale was also found to be reliable for this study $(\alpha=.74)$.

Psychological conditions (psychological meaningfulness) was found to have a relationship with: psychological conditions (psychological safety) ( $r$ $=0,61, p<0,05$; large effect); sense of calling (transcendent summons search) ( $r=-0,11, p<0,05$; small effect); sense of calling (purposeful work presence) $(r=0,61, p<0,05$; large effect); sense of calling (purposeful work search) $(r$ $=-0,30, p<0,05$; medium effect); sense of calling (prosocial orientation presence) $(r=0,50, p<0,05$; large effect); sense of calling (prosocial orientation search $)(r=-0,18, p<0,05$; small effect $)$; organisational commitment (normative commitment) $(r=0,36, p<0,05$; medium effect); and organisational commitment (affective commitment) $(r=0,28, p<0,05$; small effect). Psychological meaningfulness reported a negative relationship with turnover intention $(r=-0,35, p<0,05$; medium effect). A positive relationship was reported between psychological availability and turnover intention $(r=$ $0,61, p<0,05$; large effect).

This partly supports Hypothesis 1: psychological conditions have a negative relationship with turnover intention.

Psychological conditions (psychological availability) was found to have a relationship with: sense of calling (transcendent summons search) $(r=$ 
$-0,11, p<0,05$; small effect); sense of calling (purposeful work presence) $(r=$ $0,40, p<0,05$; medium effect); sense of calling (purposeful work search) $(r=$ $-0,21, p<0,05$; small effect); sense of calling (prosocial orientation presence) $(r=0,47, p<0,05$; large effect); sense of calling (prosocial orientation search) ( $r=-0,17, p<0,05$; small effect); organisational commitment (normative commitment) ( $r=0,24, p<0,05$; small effect); and organisational commitment (affective commitment) $(r=0,18, p<0,05$; small effect).

Hypothesis 2 was also partly supported with negative and positive relationships between sense of calling and turnover intention.

This study found that sense of calling (transcendent summons search) had a relationship with: sense of calling (purposeful work presence) $(r=0,00, p<$ 0,05 ; small effect); sense of calling (purposeful work search) $(r=0,64, p<$ 0,05 ; large effect); sense of calling (prosocial orientation presence) $(r=0,01$, $p<0,05$; small effect); sense of calling (prosocial orientation search) $(r=0,56$, $p<0,05$; large effect); organisational commitment (normative commitment) $(r$ $=0,03, p<0,05$; small effect); organisational commitment (affective commitment) $(r=-0,17, p<0,05$; small effect) and turnover intention $(r=$ $0,37, p<0,05$; medium effect).

It was found that sense of calling (purposeful work presence) $(r=0,00$, $p<0,05$; small effect) reported a relationship with: sense of calling (purposeful work search) $(r=-0,16, p<0,05$; small effect); sense of calling (prosocial orientation presence) $(r=0,58, p<0,05$; large effect); sense of calling (prosocial orientation search) $(r=-0,07, p<0,05$; small effect); organisational commitment (normative commitment) $(r=0,29, p<0,05$; small effect); organisational commitment (affective commitment) $(r=0,23, p<0,05$; small effect) and turnover intention ( $r=-0,31, p<0,05$; medium effect).

Sense of calling (purposeful work search) reported a relationship with: sense of calling (prosocial orientation presence) $(r=-0,03, p<0,05$; small effect); sense of calling (prosocial orientation search) $(r=0,78, p<0,05$; large effect); organisational commitment (normative commitment) $(r=-0,14, p<$ 0,05 ; small effect); organisational commitment (affective commitment) $(r=-$ $0,28, p<0,05$; small effect) and turnover intention $(r=0,41, p<0,05$; large effect).

In this study, sense of calling (prosocial orientation presence) reported a relationship with: sense of calling (prosocial orientation search) $(r=0,07, p$ 
$<0,05$; small effect); organisational commitment (normative commitment) $(r$ $=0,19, p<0,05$; small effect); organisational commitment (affective commitment $)(r=0,20, p<0,05$; small effect) and turnover intention $(r=-$ $0,15, p<0,05$; small effect).

It was noted that sense of calling (prosocial orientation search) reported a relationship with organisational commitment (normative commitment) ( $r=-0,15, p<0,05$; small effect); organisational commitment (affective commitment) $(r=-0,26, p<0,05$; small effect) and turnover intention $(r=0,41, p<0,05$; large effect).

Organisational commitment (normative commitment) reported a relationship with organisational commitment (affective commitment) $(r=$ $0,30, p<0,05$; medium effect) and turnover intention $(r=-0,29, p<0,05$; small effect). Organisational commitment (affective commitment) reported a negative relationship with turnover intention $(r=-0,43, p<0,05$; large effect).

This supports Hypothesis 3 indicating that organisational commitment has a negative relationship with turnover intention.

As can be seen from Table 3, below, using turnover intention as the dependent variable, Stepwise Multiple Regression was performed with psychological conditions (psychological meaningfulness), psychological conditions (psychological availability) producing a significant model in step one $\left(\mathrm{F}_{(2,274)}\right.$ $=18.35 ; p<0,00)$ and accounting for $11.9 \%$ of the variance. In Step two, sense of calling (transcendent summons search), sense of calling (purposeful work presence), sense of calling (purposeful work search), and sense of calling (prosocial orientation search) were added to produce a significant model $\left(\mathrm{F}_{(6,274)}=18.12 ; p<0,00\right)$, and account for $27.3 \%$ of the variance. In Step three, organisational commitment (affective commitment) was added to produce a significant model $\left(\mathrm{F}_{(7,274)}=22.09 ; p<0,00\right)$ and account for $35 \%$ of the variance. It appears that sense of calling (transcendent summons search) $(\beta=$ $0,20 ; t=3.13 ; p<0,00)$, sense of calling (purposeful work presence) $(\beta=-$ $0,16 ; t=-2.61 ; p<0,01)$, sense of calling (prosocial orientation search) $(\beta=$ $0,20 ; t=2.56 ; p<0,01)$, and affective commitment $(\beta=-0,30 ; t=-5.74 ; p<$ $0,00)$ are significant predictors of turnover intention.

This partially supports Hypothesis 4 indicating that sense of calling and organisational commitment are significant predictors of turnover intention. 


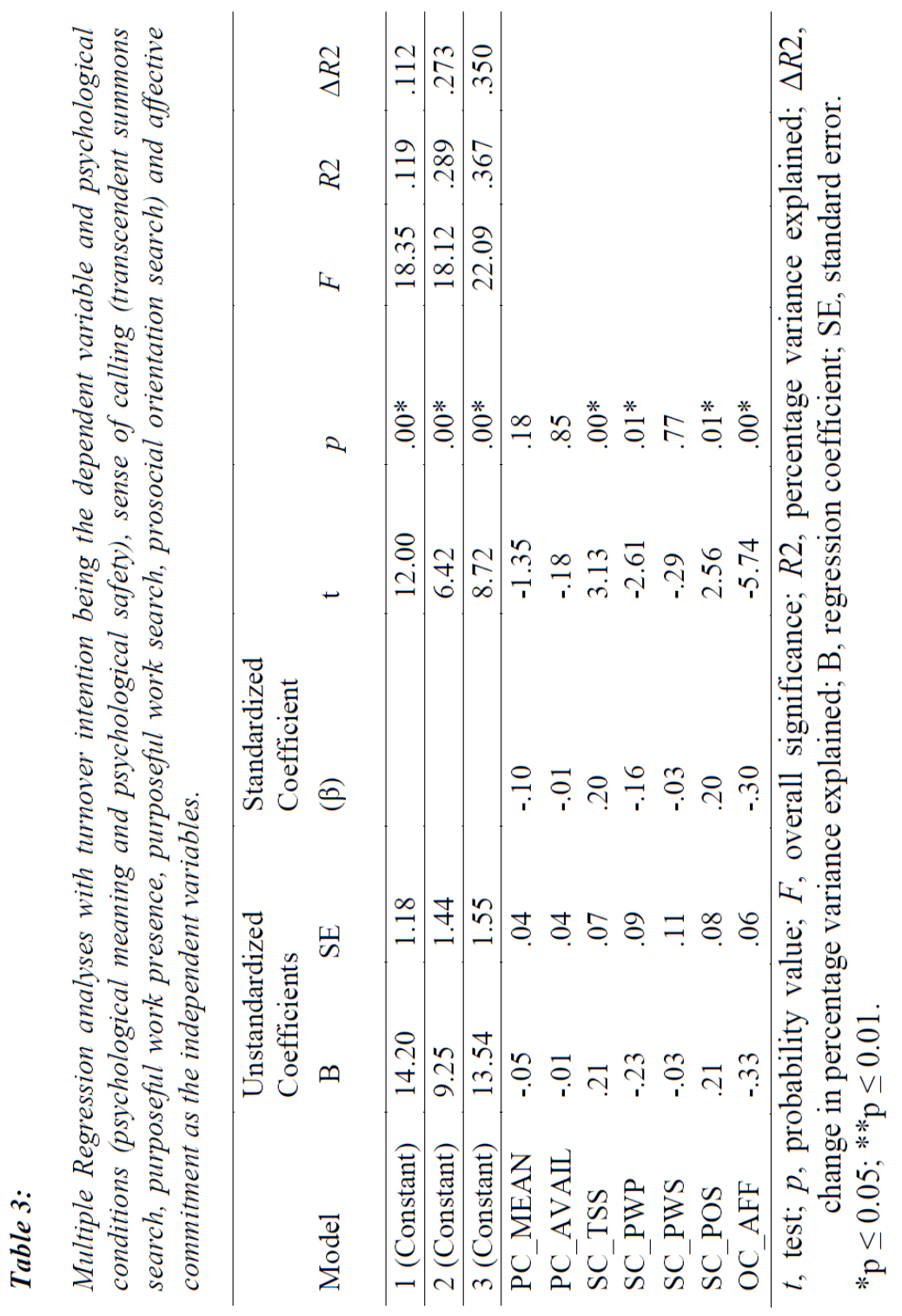




\section{Discussion}

The aim of this study was to investigate the relationship between psychological conditions, sense of calling, organisational commitment and turnover intention of teachers in Namibia. Psychological meaningfulness reported a negative relationship with turnover intention. This means that when employees experience a good work - role fit, task significance (doing work that are valued and important), are satisfied with rewards and the relations with supervisors, receive organisational support, they would experience psychological meaningfulness in their work (Allan et al. 2016; May et al. 2004; Rothmann \& Welsh 2013). When employees experience psychological meaningfulness, they would also want to remain at the organisation instead of leaving. Meaningfulness can be enhanced when there is a balance between what employees put into their work and what they get out, not only focusing on financial gains.

Employees that believe that they have the necessary job resources, skills and abilities are more likely to leave the organisation. It is commendable that the Ministry of Education, Arts and Culture strives to educate and develop teachers, but this can also add to the turnover intention rate of teachers. Continued support for growth and advancement opportunities is encouraged; it would also be beneficial to ensure that teachers utilise these skills and abilities within, and not outside, the teaching industry. This could be done through bursary agreements that would compel teachers that have been funded by the government to work for a specified period of time, and also to transfer the acquired skills to other teachers before leaving the teaching industry. Many industries and institutions have similar contractual agreements in place, however closer control and enforcement may be required.

It was found that teachers who are actively searching for their calling are more likely to leave. Their intention to leave could be because these teachers do not see teaching as their calling, but rather as a stepping stone to something else, or, in some cases, just another job.

This study also found that teachers who experience purpose in their work are more likely to stay at the organisation, and that teachers who search for purpose but do not find it within the teaching industry are likely to leave the organisation. Doing a job that is regarded as meaningless or unimportant can become demoralising resulting in turnover. Providing equitable salaries and benefits will help to retain talented teachers, and enhance the meaningfulness they experience at work. 
It was found that teachers who want to make a positive contribution to society would also be likely to leave the teaching profession if they do not identify how they can contribute to society whilst in the profession. Enhancing the importance of teaching can be done by having alumni sessions with teachers and their former learners. Through these sessions, it would be possible to see and demonstrate how teachers impact the lives of prominent and productive citizens. In turn, this would help clarify and highlight the important role that teachers play in education and in society as a whole. When teachers experience this prosocial orientation (being able to help others in society through their work), they are less likely to leave the teaching industry.

Normative commitment was found to be negatively related to turnover intention. This means that teachers are likely to remain in the industry since they feel obligated to do so. This could be as a result of the opportunity to study, have a job in a country with a high unemployment rate (sometimes without the required qualifications) or the relatively flexible working hours. It was found that affective commitment was negatively related to turnover intention. When teachers experience a positive identification with the organisation, when the teachers' goals and vision are in line with that of the organisation, teachers are less likely to leave the teaching industry. These findings are supported by studies done by O'Donnell et al. (2012) and Park et al. (2014).

\section{Recommendations}

It is thus suggested that, in order to retain teachers at schools, heads of departments, principals and officials responsible for recruitment need to be careful when selecting teachers since their work - role fit (how good the candidates' abilities and skills match the expectations of the job) would influence their task significance and overall psychological meaningfulness. In order for employees to experience meaningful work, it is suggested that employees should engage in job crafting, enhance autonomy and enhance coworker relations through team building (Fouche et al. 2017). In order to utilise psychological availability, it is suggested that a mentorship program be put in place through which tenured and qualified teachers mentor young and unqualified/ underqualified teachers. Teachers that believe that they have the necessary skills and personal resources to execute their jobs are less likely to leave; perhaps these resources can be transferred before these talented teachers leave the teaching industry. 
There is a need to cultivate purpose and meaning for teachers in education since purpose and meaning are key elements in the effort to retain talented and qualified teachers. Considering that education is the backbone of any country and the basis for solid economic growth, governments, schools, principals and teachers should continue to prioritise and support education in Namibia. The support and prioritisation of education should be reflected in budget allocations, salaries and benefits awarded to teachers. This would create a conducive working environment, and provide support to teachers at all levels. It was noted that when employees experience organisational frustration due to lack of resources, working under stringent conditions, they are likely to engage in negative work behaviour such as becoming less committed towards the goals of the organisation, and displaying aggression and intention to leave (Ugwu \& Onyishi 2017).

In order to enhance teachers' organisational commitment, it is suggested to also focus on teachers' job satisfaction. Considering that job satisfaction (satisfaction with pay, the working environment, relations with colleagues and supervisors, opportunities to utilise skills and abilities, opportunities for growth) positively impacts psychological meaningfulness, organisational commitment, and turnover intention (negatively), it is suggested that the Ministry of Education, Arts and Culture conduct a job satisfaction survey at regional and national level. This would allow the Ministry of Education to identify factors that impact job satisfaction and psychological meaningfulness, and to understand recommendations aimed at reducing turnover intention. Considering that job satisfaction differs from employee to employee, it is suggested that this evaluation be done on all teachers in Namibia. Furthermore, it is suggested that the survey should be adapted to reflect the varying region-specific factors that may impact job satisfaction. The positive impact of job satisfaction has been highlighted by other studies as well (Akomolafe \& Olatomide 2013; Chang 2015; Jena 2014; O'Donnell et al. 2012; Qureshi et al. 2017).

It is further suggested that, procedural justice should be ensured at schools as a means of enhancing organisational commitment and, in turn, reduce turnover intention. Procedural justice entails applying policies and procedures consistently and fairly throughout the organisation. Educating employees about policies and procedures enhances the perception of justice at the workplace. The relationship between procedural justice and organisational commitment was also supported by Lopez-Cabarcos et al. (2015) and Qureshi 


\section{Wesley Reginald Pieters}

Frank, Lambert, Klahm and Smith (2017).

Having the necessary organisational support enhances organisational commitment and job satisfaction. These findings were also supported by O'Donnell et al. (2012) and Shukla and Rai (2015). When employees have the necessary resources and support from the organisation, they are better equipped to complete their work activities. Considering that most schools are funded by government, and the funds are not always sufficient, it is recommended that teachers be taught about job crafting, and how to manage their work in spite of the lack of resources. The Ministry of Education, Arts and Culture may also consider a blended approach to funding since the government is experiencing challenges when it comes to providing effective free primary and secondary education to all Namibian.

Once turnover intention has been reduced, employees would also become more engaged in their work, more satisfied, more productive, resulting in teacher retention, learner satisfaction and probably better educated learners (Dane \& Brummel 2013; O’Donnell et al. 2012).

It was found that sense of calling (transcendent summons search), sense of calling (purposeful work presence), sense of calling (prosocial orientation search), and affective commitment are significant predictors of turnover intention. Teachers that search for their calling, purpose in the work that they do, want to do work that impacts society positively and identify with the organisation are least likely to leave the teaching industry.

Some of the limitations experienced when conducting this study include: some parcels not being delivered immediately to the remote schools since the delivery schedules and working hours of teachers did not always coincide. It is recommended that a similar study should also be conducted, considering a quantitative approach and investigate other factors that reduce turnover intention that were not covered by the scope and focus of this study such as job-demands resources as well as burnout levels of teachers. Subsequent to this study, a study comparing the psychological well-being of teachers and how it relates to sense of calling and intention to leave is recommended.

\section{Conclusion}

This study found positive relations between psychological conditions (psychological availability); sense of calling (transcendent summons search; 
purposeful work search; search for prosocial orientation) and turnover intention. Turnover intention reported a negative relationship with psychological meaningfulness; sense of calling (purposeful work presence; prosocial orientation presence); and affective commitment.

Sense of calling (transcendent summons search; purposeful work presence; prosocial orientation search), and affective commitment are significant predictors of turnover intention. These variables explained $35 \%$ of the variance in turnover intention for the sampled population. By focusing on these variables, turnover intention can be reduced by one-third and hopefully reduce the frustration within schools regarding the learner-teacher ratio. By focusing on these recommendations, the number and frequency of vacancies may also be reduced since teachers may want to remain in education.

Based on the findings of this study and the literature discussed, if schools (ministry of education) are able to enhance the meaning, purpose and significance of education, and the importance of teaching, teachers would want to remain in education (commitment) and contribute to the success of the school (education system).

\section{Acknowledgments}

The researcher would also like to express his gratitude to the teachers within the Ministry of Education, Arts and Culture for their accommodating and generous nature with which they engaged in this study.

\section{References}

Akomolafe, M. J. \& O.O. Olatomide 2013. Job Satisfaction and Emotional Intelligence as Predictors of Organisational Commitment of Secondary School Teachers. Ife PsychologIA 21,2: 65 - 74. Available at https://pdfs.semanticscholar.org/531a/88f1e50bd819925f7a65891fe88c9 9f37e0e.pdf. (Accessed on 18 November 2017.)

Allan, B.A., R.D. Duffy \& B. Collisson 2016. Task Significance and Performance: Meaningfulness as a Mediator. Journal of Career Assessment, 1: 1 - 11. Available at: http://journals.sagepub.com/doi/abs/10.1177/1069072716680047

(Accessed on 18 November 2017.) https://doi.org/10.1177/1069072716680047 
Allen, N.J. \& J.P. Meyer 1996. Affective, Continuance, and Normative Commitment to the Organization: An Examination of Construct Validity. Journal of Vocational Behavior 49,3: 252 - 276. Available at: https://www.sciencedirect.com/science/article/pii/S0001879196900433 (Accessed on 18 November 2017.) https://doi.org/10.1006/jvbe.1996.0043

Bellah, R., R. Madsen, W. Sullivan, A. Swidler \& S. Tipton 1985. Habits of the Heart: Individualism and Commitment in American Life. Berkeley, CA: University of California Press.

Berg, J.M., J.E. Dutton \& A. Wrzesniewski 2013. Job Crafting and Meaningful Work. In Dik, B., Z. Byrne \& M. Steger (eds.): Purpose and Meaning in the Workplace. Washington, DC: American Psychological Association.

Bothma, C.F.C. \& G. Roodt 2013. The Validation of the Turnover Intention Scale. South African Journal of Human Resource Management 11,1: 1 12. Available at:

https://sajhrm.co.za/index.php/sajhrm/article/view/507/602 (Accessed on 18 November 2017.)

https://doi.org/10.4102/sajhrm.v11i1.507

Brunetto, Y., S.T. Teo, K. Shacklock \& R. Farr-Baharton 2012. Emotional Intelligence, Job Satisfaction, Well-being and Engagement: Explaining Organisational Commitment and Turnover Intentions in Policing. Human Resource Management Journal 22,4: 428 - 441. Available at: http://onlinelibrary.wiley.com/doi/10.1111/j.1748-

8583.2012.00198.x/abstract;jsessionid=66F49275E4A76DB50D9385A

CBA812C04.f02t01 (Accessed on 18 November 2017.)

https://doi.org/10.1111/j.1748-8583.2012.00198.x

Campbell, J.W. \& T. Im 2016. PSM and Turnover Intention in Public Organisations: Does Change-oriented Organisational Citizenship Behavior Play a Role? Review of Public Personnel Administration 36,4: 323 - 346. Available at:

http://journals.sagepub.com/doi/pdf/10.1177/0734371X14567366 (Accessed on 18 November 2017.) https://doi.org/10.1177/0734371X14567366

Chang, C. 2015. Moderating Effects of Nurses' Organizational Support on the Relationship between Job Satisfaction and Organisational Commitment. Western Journal of Nursing Research 37,6: 724 - 745. Available at: http://journals.sagepub.com/doi/abs/10.1177/0193945914530047 
(Accessed on 18 November 2017.)

https://doi.org/10.1177/0193945914530047

Chen, J., D.R. May, C.E. Schwoerer \& B. Augelli 2016. Exploring the Boundaries of Career Calling: The Moderating Roles of Procedural Justice and Psychological Safety. Journal of Career Development 1:1 14. Available at:

http://journals.sagepub.com/doi/abs/10.1177/0894845316671214

(Accessed on 18 November 2017.)

https://doi.org/10.5465/ambpp.2015.12365abstract

Cho, Y. J. \& H.J. Song 2017. Determinants of Turnover Intention of Social

Workers: Effects of Emotional Labour and Organisational Trust. Public

Personnel Management 46, 1: 41 - 65. Available at:

http://journals.sagepub.com/doi/abs/10.1177/0091026017696395

(Accessed on 18 November 2017.)

https://doi.org/10.1177/0091026017696395

Choudhury, R.R. \& V. Gupta 2011. Impact of Age on Pay Satisfaction and Job

Satisfaction Leading to Turnover Intention: A Study of Young Working

Professionals in India. Management and Labour Studies 36,4: 353 - 363.

Available at:

http://journals.sagepub.com/doi/abs/10.1177/0258042X1103600404

(Accessed on 18 November 2017.)

https://doi.org/10.1177/0258042X1103600404

Cohen, J. 1988. Statistical Power Analysis for the Behavioural Sciences.

Revised Edition. Orlando, CA: Academic Press.

Creswell, J.W. 2003. Research Design: Qualitative, Quantitative, and Mixed Methods Approaches. $2^{\text {nd }}$ Edition. London: Sage Publications.

Dane, E. \& B.J. Brummel 2013. Examining Workplace Mindfulness and its Relations to Job Performance and Turnover Intention. Human Relations 67,1: 105 - 128. Available at:

http://journals.sagepub.com/doi/abs/10.1177/0018726713487753

(Accessed on 18 November 2017.)

https://doi.org/10.1177/0018726713487753

Dik, B.J., B.M. Eldridge, M.F. Steger \& R.D. Duffy 2012. Development and

Validation of the Calling and Vocation Questionnaire (CVQ) and Brief Calling Scale (BCS). Journal of Career Assessment 20,3: 242 - 263. Available at:

http://journals.sagepub.com/doi/abs/10.1177/1069072711434410 
(Accessed on 18 November 2017.)

https://doi.org/10.1177/1069072711434410

Fouche, E., S. Rothmann \& C. van der Vyver 2017. Antecedents and Outcomes of Meaningful Work among School Teachers. South African Journal of Industrial Psychology 43: 1 - 10. Available at: http://www.sajip.co.za/index.php/sajip/article/view/1398 (Accessed on 18 November 2017.) https://doi.org/10.4102/sajip.v43i0.1398

Haufiku, M. 2014. 18000 Teachers, Nurses and Cops Needed. Available at: https://www.newera.com.na/2014/10/31/18-000-teachers-nurses-copsneeded/ (Accessed on 07 August 2017.)

Hirschi, A. 2011. Callings in Career: A Typological Approach to Essential and Optional Components. Journal of Vocational Behavior 79: 60 - 73.

Available at:

http://www.andreashirschi.com/publicationsblog/2015/7/30/callings-incareer-a-typological-approach-to-essential-and-optional-components (Accessed on 18 November 2017.) https://doi.org/10.1016/j.jvb.2010.11.002

Huang, C., C. You \& M. Tsai 2012. A Multidimensional Analysis of Ethical Climate, Job Satisfaction, Organisational Commitment and Organisational Citizenship Behaviors. Nursing Ethics 19,4: 513 - 529.

Available at:

http://journals.sagepub.com/doi/abs/10.1177/0969733011433923

(Accessed on 18 November 2017.)

https://doi.org/10.1177/0969733011433923

Jena, R.K. 2014. The Effects of Job Satisfaction on Organisational Commitment among Shift Workers: A Field Study of Ferro-alloy Industries. Asia-pacific Journal of Management Research and Innovation 10,2: 109 - 118. Available at:

http://journals.sagepub.com/doi/abs/10.1177/2319510X14536218

(Accessed on 18 November 2017.)

https://doi.org/10.1177/2319510X14536218

Kahn, W.A. 1990. Psychological Conditions of Personal Engagement and Disengagement at Work. Academy of Management Journal 33: 692 - 724. Available at: http://amj.aom.org/content/33/4/692.short (Accessed on 18 November 2017.) https://doi.org/10.5465/256287

Kim, J. 2015. What Increases Public Employees' Turnover Intention? Public Personnel Management 44,4: 496 - 519. Available at: 
http://journals.sagepub.com/doi/abs/10.1177/0091026015604447

(Accessed on 18 November 2017.)

https://doi.org/10.1177/0091026015604447

Kim, H. \& M. Stoner 2008. Burnout and Turnover Intention among Social Workers: Effects of Role Stress, Job Autonomy and Social Support. Administration in Social Work 32,3: 5 - 25. Available at:

http://www.tandfonline.com/doi/abs/10.1080/03643100801922357

(Accessed on 18 November 2017.)

https://doi.org/10.1080/03643100801922357

Lopez-Cabarcos, M.A., A.I.M. Pinho \& P. Vazquez-Rodriquez 2015. The

Influence of Organisational Justice and Job Satisfaction on Organisational Commitment in Portugal's Hotel Industry. Cornell Hospitality Quarterly 56,3: 258 - 272. Available at:

http://journals.sagepub.com/doi/abs/10.1177/1938965514545680

(Accessed on 18 November 2017.)

https://doi.org/10.1177/1938965514545680

Mensele, C. \& M. Coetzee 2014. Job Embeddedness, Organisational Commitment and Voluntary Turnover of Academic Staff at a Higher Education Institution in South Africa. South African Journal of Labour Relations 38,1: 9 - 30. Available at:

http://uir.unisa.ac.za/handle/10500/13728 (Accessed on 18 November 2017.)

Marques, L.A. 2013. Antecedents and Outcomes of Work-related Psychological Well-being of Staff Members of the University of Namibia. Unpublished Doctoral Dissertation, University of Namibia, Windhoek. Available at: http://repository.unam.na/handle/11070/926 (Accessed on 18 November 2017.)

May, D.R., R.I. Gilson \& L.M. Harter 2004. The Psychological Conditions of

Meaningfulness, Safety and Availability and the Engagement of the Human Spirit at Work. Journal of Occupational and Organizational Psychology 77: 11 - 37. Available at:

http://onlinelibrary.wiley.com/doi/10.1348/096317904322915892/abstra ct (Accessed on 18 November 2017.)

https://doi.org/10.1348/096317904322915892

Medina, E. 2012. Job Satisfaction and Employee Turnover Intention: What does Organizational Culture have to do with It? Unpublished Master's thesis, Columbia University, New York City, Manhattan. Available at: 
https://academiccommons.columbia.edu/catalog/ac\%3A156625

(Accessed on 18 November 2017.)

Meyer, J.P. \& N.J. Allen 1984. Testing the 'side bet theory' of Organisational

Commitment: Some Methodological Considerations. Journal of Applied Psychology 69: 372 - 378. Available at:

http://psycnet.apa.org/record/1984-32952-001 (Accessed on 18

November 2017.) https://doi.org/10.1037/0021-9010.69.3.372

Nambundunga, M. 2016. Factors that Influence Teacher Attrition in

Secondary Schools in the Omusati Education Region, Namibia.

Unpublished Master's thesis, University of Namibia, Windhoek.

Available at: http://repository.unam.na/handle/11070/1996 (Accessed on

18 November 2017.)

Nouri, H. \& R.J. Parker 2013. Career Growth Opportunities and Employee

Turnover Intentions in Public Accounting Firms. The British Accounting

Review 45,2: 138 - 148. Available at:

https://www.sciencedirect.com/science/article/pii/S0890838913000188

(Accessed on 18 November 2017.)

https://doi.org/10.1016/j.bar.2013.03.002

O’Donnell, M., A.K.L. Jayawardana \& J.A.S.K. Jayakody 2012.

Organisational Support and Employee Commitment in Sri Lanka. The Economic and Labour Relations Review 23,1: 125 - 142. Available at: http://journals.sagepub.com/doi/abs/10.1177/103530461202300108

(Accessed on 18 November 2017.)

https://doi.org/10.1177/103530461202300108

O'Neal, A.M. 2017. The Effects of Calling and Vocational Presence and

Search on Psychological Well-being. Unpublished Doctoral Thesis,

Graduate College pf Bowling Green State University, Ohio. Available at: https://etd.ohiolink.edu/!etd.send file?accession=bgsu149096095782599 $1 \&$ disposition=inline (Accessed on 18 November 2017.)

Park, H.Y., R.L. Christie \& G.E. Sype 2014. Organisational Commitment and Turnover Intention in Union and Non-union Firms. SAGE Open JanuaryMarch: 1 - 11. Available at:

http://journals.sagepub.com/doi/abs/10.1177/2158244013518928.

(Accessed on 18 November 2017.)

https://doi.org/10.1177/2158244013518928

Paul, H., U.K. Bamel \& P. Garg 2016. Employee Resilience and OCB: Mediating Effects of Organisational Commitment. The Journal for 
Decision Makers 41,4: 308 - 324. Available at:

http://journals.sagepub.com/doi/abs/10.1177/0256090916672765

(Accessed on 18 November 2017.)

https://doi.org/10.1177/0256090916672765

Price, J. 2001. Reflections on the Determinants of Voluntary Turnover. International Journal of Manpower 22: 600 - 624. Available at: http://www.emeraldinsight.com/doi/full/10.1108/EUM0000000006233

(Accessed on 18 November 2017.)

https://doi.org/10.1108/EUM0000000006233

Qureshi, H., J. Frank, E.G. Lambert, C. Klahm \& B. Smith 2017. Organisational Justice's Relationship with Job Satisfaction and Organisational Commitment among Indian Police. Police Journal 90,1: 3 - 23. Available at:

http://journals.sagepub.com/doi/abs/10.1177/0032258X16662684

(Accessed on 18 November 2017.)

https://doi.org/10.1177/0032258X16662684

Regts, G. \& E. Molleman 2013. To Leave or Not to Leave: When Receiving Interpersonal Citizenship Behavior Influences an Employee's Turnover Intention. Human Relations 66,2: 193 - 218. Available at:

http://journals.sagepub.com/doi/abs/10.1177/0018726712454311

(Accessed on 18 November 2017.)

https://doi.org/10.1177/0018726712454311

Rothmann, S., E. Diedericks \& J.P. Swart 2013. Manager Relations,

Psychological Need Satisfaction and Intention to Leave in the Agricultural Sector. South African Journal of Industrial Psychology 39,2: 1 - 14. Available at:

https://www.researchgate.net/publication/256169041_Manager_relations psychological need satisfaction and intention to leave in the agric ultural_sector (Accessed on 18 November 2017.)

https://doi.org/10.4102/sajip.v39i2.1129

Rothmann, S. \& L. Hamukang'andu 2013. Callings, Work Role Fit, Psychological Meaningfulness and Work Engagement among Teachers in Zambia. South African Journal of Education 33,2: 1 - 16. Available at: https://www.ajol.info/index.php/saje/article/viewFile/88408/78019

(Accessed on 18 November 2017.)

https://doi.org/10.15700/saje.v33n2a699

Rothmann, S. \& C. Welsh 2013. Employee Engagement: The Role of Psycho- 
logical Conditions. Management Dynamics 22,1: 14 - 25. Available at: https://journals.co.za/content/mandyn/22/1/EJC133395 (Accessed on 18 November 2017.)

Shukla, A. \& H. Rai 2015. Linking Perceived Organisational Support to Organisational Trust and Commitment: Moderating Role of Psychological Capital. Global Business Review 16,6: 981 - 996. Available at: $\quad$ http://journals.sagepub.com/doi/abs/10.1177/0972150915597599 (Accessed on 18 November 2017.)

https://doi.org/10.1177/0972150915597599

Simons, J.C. \& J.H. Buitendach 2013. Psychological Capital, Work Engagement and Organisational Commitment amongst Call Centre Employees in South Africa. South African Journal of Industrial Psychology 39,2: 1 - 12. Available at:

http://www.sajip.co.za/index.php/sajip/article/view/1071/1469

(Accessed on 18 November 2017.)

https://doi.org/10.4102/sajip.v39i2.1071

SPSS 2016. SPSS 24.0 for Windows. Chicago, IL: SPSS Incorporated.

Steyn, H.S. 1999. Praktiese Betekenisvolheid: Die Gebruik van Effekgroottes.

Wetenskaplike bydraes - Reeks B: Natuurwetenskappe Nr. 117.

Potchefstroom: PU vir CHO.

Teaching Posts 2018. Available at:

http://www.informante.web.na/uploads/pdfs/TeachingPosts.pdf on 29

November 2017.

Ugwu, F.O. \& I.E. Onyishi 2017. Linking Perceived Organizational

Frustration to Work Engagement: The Moderating Roles of Sense of

Calling and Psychological Meaningfulness. Journal of Career Assessment

1: 1 - 20. Available at:

http://journals.sagepub.com/doi/abs/10.1177/1069072717692735

(Accessed on 18 November 2017.)

Viljoen, J.P. \& S. Rothmann 2009. Occupational Stress, Ill Health and Organisational Commitment of Employees at a University of Technology. South African Journal of Industrial Psychology 35,1: 1 - 11. Available at: http://sajip.co.za/index.php/sajip/article/view/730 (Accessed on 18 November 2017.) https://doi.org/10.4102/sajip.v35i1.730

Willemse, M. \& E. Deacon 2015. Experiencing a Sense of Calling: The Influence of Meaningful Work on Teachers' Work Attitudes. South African Journal of Industrial Psychology 41,1: 1 - 9. Available at: 
http://www.sajip.co.za/index.php/sajip/article/view/1274/1834

(Accessed on 18 November 2017.)

https://doi.org/10.4102/sajip.v41i1.1274

Wrzesniewski, A. \& J.E. Dutton 2001. Crafting a Job: Previsioning Employees as Active Crafters of their Work. Academy of Management Review 26: 179 - 201. Available at:

http://faculty.som.yale.edu/amywrzesniewski/documents/Craftingajob_R evisioningemployees_000.pdf (Accessed on 18 November 2017.)

https://doi.org/10.5465/amr.2001.4378011

Wrzesniewski, A., N. LoBuglio, J.E. Dutton \& J.M. Berg 2013. Job Crafting and Cultivating Positive Meaning and Identity in Work. Advances in Positive Organizational Psychology 1: 281 - 302. Available at:

http://justinmberg.com/wrzesniewski-lobuglio-dutto.pdf

(Accessed on 18 November 2017.)

https://doi.org/10.1108/S2046-410X(2013)0000001015

Xaba, M.I. 2003. Managing Teacher Turnover. South African Journal of Education 23,4: 287 - 291. Available at:

https://www.ajol.info/index.php/saje/article/viewFile/24948/20633

(Accessed on 18 November 2017.)

Wesley Reginald Pieters

University of Namibia

Windhoek

Namibia

wpieters@unam.na 